\title{
ANALISIS PENGELOLAAN KREDIT PADA PT. BANK PERKREDITAN RAKYAT GANTO NAGARI 1954 LUBUK ALUNG KABUPATEN PADANG PARIAMAN
}

\author{
Intan Puspita Dewi, Jhon Fernos \\ Akademi Keuangan dan Perbankan "Pembangunan" \\ Puspitadewiintan626@gmail.com
}

\begin{abstract}
The purpose of this study is to inscrease knowledge about how to analyze credit management at PT. Bank Perkreditan Rakyat Ganto Nagari 1954 Lubuk Alung Kabupaten Padang Pariaman. The method of data analysis is using quantitative data and qualitative data as a research method. From the results of the study for the 20172018 period, the number of non-performing loans has decreased by $30 \%$ and in the 2018-2019 period there has been another decline of 0.70\% and this proves that the credit management carried out has been running smoothly good.
\end{abstract}

Keywords: management credit, Bank

\section{PENDAHULUAN}

Menurut Lubis (2010) Bank dan lembaga keuangan lainnya merupakan institusi yang berdampak penting dalam penentuan sebuah kelancaran aktifitas perekonomian dan keberhasilan pembangunan. Serta menurut Undang-Undang No.10 Tahun 1998 Tentang Perbankan, Bank ialah badan usaha yang menghimpun dana dari masyarakat dalam bentuk simpanan dan menyalurkannya kepada masyarakat dalam bentuk kredit dan bentuk-bentuk lainnya.

Dalam Undang-Undang No 10 Tahun 1998 tentang perbankan, berdasarkan macam bank mencakup Bank umum dan Bank Perkreditan Rakyat (BPR). Bank umum ialah bank yang melakukan aktivitas bisnis secara konvensional atau berdasarkan prinsip syariah yang dalam langkahnya memberikan jasa dalam lalu lintas pembayaran. Bank Perkreditan Rakyat adalah Bank yang melakukan aktivitas bisnis secara konvensional atau prinsip syariah yang dalam aktivitasnya tidak melakukan jasa dalam lalu lintas pembayaran.

Menurut Alanshari dan Marlius (2018) kredit yaitu sesuatu yang diperlukan bagi masyarakat untuk menghidupkan dan melajukan aktivitas perdagangan, baik pada bagian memproduksi barang ataupun jasa serta untuk meningkatkan maupun memenuhi keperluan konsumsi masyarakat.

Menurut Kasmir (2014) Sesuai dengan pengertian kredit yaitu penyediaan uang berdasarkan kesepakatan pinjam meminjam, ini berarti perlu adanya akad atau perjanjian kredit. Pengesahan kredit ini hendak mengikat bank dan debitur. 
Pengelolaan kredit adalah kredit yang pengelolaannya bisa diperhatikan mulai penyaluran kredit yang menganalisis secara lanjut calon debitur serta memakai metode 5C (Character, Capacity, Capital, Collateral, Condition of Economy,) dan 7P (Personality, Party, Purpose, Prospect, Payment, Profitability, Protection) serta 3R ( Return, Repayment, Risk) dalam rangka untuk penanganan kredit yang baik dan menghindari Kredit macet (Al Qoroni 2015).

PT. Bank Perkreditan Rakyat Ganto Nagari 1954 Lubuk Alung Kabupaten Padang Pariaman sebagai lembaga yang berfokus terhadap pelayanan transaksi ekonomi masyarakat menengah ke bawah, karena itu PT. Bank Perkreditan Rakyat Ganto Nagari 1954 Lubuk Alung Kabupaten Padang Pariaman terus berusaha meningkatkan kualitas modal dan sumber daya manusia, mendorong pembangunan ekonomi melalui penghimpunan dana yang terarah dengan produk tabungan dan deposito serta membantu pembangunan usaha kecil dan mikro melalui pemberian kredit.

Tabel 1

Data Perkembangan Kredit

PT. Bank Perkreditan Rakyat Ganto Nagari 1954

Lubuk Alung Kabupaten Padang Pariaman

(dalam Rp.000,-)

\begin{tabular}{ccc}
\hline \multicolumn{1}{l}{ Tahun } & $\begin{array}{c}\text { Jumlah Pinjaman } \\
\text { Yang Diberikan }\end{array}$ & Kredit Bermasalah \\
\hline 2017 & $21.895,300$ & $1.263,359$ \\
2018 & $23.476,193$ & 896,791 \\
2019 & $23.683,474$ & 890,499 \\
\hline
\end{tabular}

Sumber: www. Ojk.com

Pada Tabel 1 terlihat pada tahun 2017 jumlah pinjaman yang diberikan adalah sebesar Rp.21.895,300.000,- dan kredit bermasalah sebesar Rp.1.263,359.000,- dan kemudian pada tahun 2018 jumlah pinjaman yang diberikan sebesar Rp.23.476,193.000,- dan kredit bermasalah sebesar Rp.896,791.000,- selanjutnya pada tahun 2019 jumlah pinjaman yang diberikan sebesar Rp.23.683,474.000,- dan kredit bermasalah yang terjadi sebesar Rp.890,499.000,-

Berdasarkan uraian diatas, maka penulis merumuskan permasalahan yang akan diteliti yaitu Bagaimana Analisis Pengelolaan Kredit pada PT. Bank Perkreditan Rakyat Ganto Nagari 1954 Lubuk Alung Padang Pariaman.

\section{METODE PENELITIAN}

Dalam pengumpulan data dan bahan untuk penelitian ini digunakan metode penelitian yaitu:

1. Metode Pengumpulan Data

a. Teknik Wawancara (Field Research)

Artinya, penulis langsung bekerja dilapangan untuk membantu penulis dalam melengkapi data-data, metode ini merupakan melalui tanya jawab 
pada pihak tertentu di perusahaan terkait.

b. Teknik Kepustakaan (Library Research)

Yaitu penelitian dilakukan di perpustakaan, beberapa buku ilmiah, dan karya sesuai prosedur diskusi yang dilakukan.

2. Metode Analisis Data

Melaksanakan analisa data, menggunakan analisa data kuantitatif. Dimana metode Kuantitatif menganalisis laporan keuangan pada PT. Bank Perkreditan Rakyat Ganto Nagari 1954 Lubuk Alung Kabupaten Padang Pariaman.

\section{HASIL DAN PEMBAHASAN Pengertian Bank}

Undang-Undang Republik Indonesia Nomor 10 tahun 1998 pasal 1 ayat (2) menyatakan Bank ialah lembaga bisnis yang menghimpun dana dari masyarakat dalam bentuk simpanan dan menyalurkannya kepada masyarakat dalam bentuk kredit dan atau bentuk-bentuk lainnya dalam bentuk mengembangkan taraf hidup rakyat banyak (Widayati and Mendari 2019).

Pengertian Bank Perkreditan Raktat

Undang-Undang No.10 Tahun 1998 Tentang Perbankan, Bank Perkreditan Rakyat adalah Bank yang melakukan aktivitas bisnis secara konvensional atau prinsip syariah yang dalam aktivitasnya tidak melakukan jasa dalam lalu lintas pembayaran.

\section{Pengertian Kredit}

Pemberian uang maupun tagihan beralaskan perjanjian pinjam meminjam antara bank dan pihak lain yang pada hal ini pihak debitur bertanggung jawab melunasi bebannya sesudah jangka waktu yang disetujui dengan basaran bunga yang ditentukan terlebih dahulu (Widayati and Maiwati 2019).

\section{Fungsi Kredit}

Menurut Widayati and Andani (2019) kredit memiliki beberapa fungsi dalam kehidupan perekonomian dan perdagangan antara lain sebagai berikut :

a. Dapat menjadi alat pertukaran yang sangat efektif

b. Untuk menyalurkan dana dan pembinaan bagi dunia usaha

c. Untuk pengawas moneter

d. Sebagai pendorong perekonomiaan dan menstabilkan ekonomi

e. Agar meningkatkan penggunaan barang dan jasa

f. Untuk alat penyalur bisnis internasional

g. Sebagai pemerataan pendapatan

h. Untuk menghindari terjadinya pemutusan financial

\section{Jenis-Jenis kredit}

Menurut Widyaningrum (2010) terdapat jenis-jenis kredit berdasarkan pengelompokan antara lain:

a. Berdasarkan tujuan dan kegunaannya

1) Kredit Konsumtif 
Adalah kredit untuk kebutuhan rumah tangga atau pembelian barang yang dibutuhkan bertujuaan untuk memberikan kepuasan bagi debitur.

2) Kredit Modal Kerja

Adalah kredit untuk penambahan modal bagi pengusaha yang sedang menjalankan usahanya bertujuan untuk meningkatkan usahanya.

3) Kredit Investasi

Adalah kredit untuk pembelian barang-barang yang berguna untuk masa yang lama bertujuan untuk investasi.

b. Berdasarkan Jangka Waktu

1) Kredit Jangka Pendek

Ialah kredit yang memiliki tenggang waktu paling lama 1 tahun ataupun minim dari 1 tahun

2) Kredit Jangka Menengah

Ialah kredit yang memiliki tenggang waktu 1 tahun mencapai 3 tahun

3) Kredit Jangka Panjang

Ialah kredit yang memiliki tenggang waktu yang paling lama yaitu lebih dari 3 tahun.

c. Berdasarkan Sektor Perekonomian

1) Kredit Pertanian

Yaitu kredit yang diserahkan pada pihak pertanian bertujuan untuk meningkatkan hasil dari produksi pertanian.

2) Kredit Perindustrian

Yaitu kredit yang diserahkan bagi aktivitas perindustrian baik dalam mekanik maupun kimia mulai dari bahan sampai menjadi barang.

3) Kredit Pertambangan

Yaitu kredit yang diserahkan guna untuk keperluan pengambilan bahanbahan tambang.

4) Kredit Ekspor dan Impor

Yaitu kredit yang diserahkan kepada eksportir juga importir

5) Kredit Koperasi

6) Kredit Profesi

d. Berdasarkan Macamnya

1) Kredit Askep

Kredit ini biasanya kredit yang diserahkan oleh bank dengan pinjaman sebanyak plafon kreditnya.

2) Kredit Penjual

Biasanya kredit yang diserahkan oleh penjual kepada pembeli yang mana barang sudah diterima dan pembayaran dilakukan setelahnya.

3) Kredit Pembeli

Kredit ini biasanya melaksanakan penyetoran pertama dahulu dan setelah itu barang diterima atau bisa juga disebut pemberian uang muka.

e. Berdasarkan Golongan Ekonomi

1) Golongan Ekonomi Lemah, 
Contohnya untuk usaha KUK dan KUT.

2) Golongan Ekonomi Menengah dan Konglomerat

Kredit ini biasanya diberikan untuk para pengusaha besar.

f. Berdasarkan Agunan atau jaminan

1) Kredit Agunan/Jaminan orang

2) Kredit Agunan/Jamina efek, surat-surat berharga

3) Kredit Agunan/Jaminan barang

4) Kredit Agunan/Jaminan dokumen

g. Berdasarkan sumber dananya

1) Kredit dananya berasal dari tabungan masyarakat.

Kredit ini diberikan karena ada dana yang berlebih dari dana masyarakat yang terkumpul melalui saving deposit.

2) Kredit dananya berasal dari penciptaan uang baru

Kredit ini diberikan dengan dana dari penambahan uang terhadap uang yang beredar atau yang telah ada.

h. Berdasarkan Penarikan atau Pelunasan

1) Kredit Rekening Koran

Kredit ini biasanya dapat dilakukan penarikan dan pelunasannya setiap waktu.

2) Kredit Berjangka

Kredit ini hanya bisa dilakukan sudah tiba jangka waktunya, kredit ini penarikannya sekaligus sebesar plafondnya.

\section{Prinsip-Prinsip Pemberian kredit}

Menurut Guntara and Griadhi (2017) Prinsip-Prinsip dasar pemberian kredit dalam dunia perbankan dikenal dengan prinsip $5 \mathrm{C}$ terdiri dari:

a. Character

Yaitu bagaimana dengan sifat, watak, pribadi dari seorang yang diberi kredit apakah dia baik dan jujur, jika nanti ada masalah pada di kemudian hari pihak bank tidak akan kesulitan.

b. Capacity

Yaitu bagaimana kemampuan dari seorang nasabah dalam memanajemenkan usahanya dengan baik, sehingga bank mampu memberikan kepercayaan kepada nasabah untuk melunasi pinjaman sesuai batas waktu yang diberikan

c. Capital

Yaitu bagaimana seorang nasabah dalam menjalankan modalnya apakah efektif atau tidak sehingga dapat menjalankan modal sesuai dengan penempatan modal tersebut.

d. Collateral

Yaitu bagaimana agunan yang diberikan oleh seorang debitur untuk menghindarkan resiko yang mungkin terjadi, jaminan tersebut haruslah berkualitas tinggi sesuai besar jumlah pinjaman yang dipinjam.

e. Condition of economy 
Yaitu bagaimana kondisi ekonomi dari seorang nasabah dan prospek usahanya untuk kedepan dan juga memperkecil resiko yang akan terjadi diakibatkan oleh kondisi ekonomi.

Penilaian kredit dalam dunia perbankan dengan prinsip 7P terdiri dari:

a. Personality

Yaitu penilaian nasabah dari segi kepribadian bagaimana sikap nasabah keseluruhan mencangkup sikap sehari-hari.

b. Party

Yaitu penggolongan nasabah sesuai dengan kondisi ekonominya, mengklasifikasi nasabah bersumber pada modal yang dimiliki, kepribadian dan loyalitas.

c. Purpose

Yaitu tujuan dari calon nasabah dalam mengajukan kreditnya untuk apa dana tercantum digunakan untuk modal usaha investasi atau biaya-biaya lainnya.

d. Prospect

Yaitu bagaimana calon nasabah dalam kemampuan membayar kredit yang akan diajukan dan kelancaran usahanya, untuk meyakinkan pihak bank.

e. Profitability

Yaitu kemampuan nasabah dalam menghasilkan untung atau laba dan memperluas usaha yang dijalankan.

f. Protection

Yaitu berupa agunan yang diberikan oleh calon peminjam seperti aset rumah atau perusahaan dan juga berupa agunan asuransi yang dimiliki oleh calon peminjam.

Penilaian kredit dalam dunia perbankan dengan prinsip 3R

a. Return

Yaitu penilaian dari hasil yang akan dicapai setelah diberikan kredit oleh pihak bank. Apakah hasil tersebut menutupi pinjaman dan usaha yang dijalankan serta berkembang atau tidak usaha yang dijalankan.

b. Repayment

Yaitu penilaian bagaimana rentang waktu perusahaan pemohon kredit dapat membayar kembali pinjamannya sesuai dengan kemampuan.

c. Risk Bearing ability

Yaitu bagaimana kemampuan untuk menanggung resiko kegagalan andai terjadi sesuatu yang tak diinginkan.

\section{Pengertian Pengelolaan Kredit}

Menurut Widyaningrum (2010) pengelolaan kredit adalah usaha-usaha untuk menjaga kredit yang diberikan tetap lancar, produktif dan tidak macet. Pengelolaan kredit sangatlah penting bagi pihak lembaga keuangan seperti bank karena kredit adalah sumber pendapatan utama bagi perbankan dan kredit sangat berpengaruh besar 
dalam pengembangan sebuah perbankan, mulai dari kredit disalurkan sampai kredit tersebut selesai atau lunas.

\section{Pembahasan}

\section{Analisis Pengelolaan Kredit pada PT. Bank Perkreditan Rakyat Ganto Nagari 1954 Lubuk Alung Kabupaten Padang Pariaman Perencanaan Kredit}

Perencanaan kredit adalah proses awal dari menetapkan langkah apa yang dilakukan pada masa yang akan datang agar mencapai tujuan dan sasaran yang diinginkan. Dalam perencanaan kredit apakah suatu kegiatan itu berhasil untuk mencapai tujuan bank atau tidak dan perencanaan itu harus dibuat sebaik mungkin agar mendapatkan hasil yang diinginkan.

Banyak elemen yang mesti dilihat dalam perencanaan kredit berguna agar perencanaanya berjalan dengan baik yaitu bagaimana kondisi ekonomi dan moneter secara makro, aktivitas pasar modal dan badan finansial lainnya, keadaan bank yang bisa didapati melalui SWOT analysis dan bank performance analysis, kemampuan nasabah dan manajemen bank, komposisi dana dan kemampuan bank dalam menghimpun dana, strategi bisnis bank, resiko perkreditan, resiko politik, itu yang mesti diamati dalam perencanaan kredit.

Pada PT. Bank Perkreditan Rakyat Ganto Nagari 1954 Lubuk Alung Kabupaten Padang Pariaman dalam perencanaan kredit yang harus diperhatikan yaitu pertimbangan suatu rencana kredit yang mantap dan terarah, bagaimana kondisi perekonomian dan perdagangan dengan mempertimbangkan barangkali yang akan keluar di dalam perencanaan tersebut, bagaimana keadaan nasabah, pihak bank harus dengan jelas mengetahui berapa jumlah dana yang tersedia dan benar-benar bisa dilepas, dan diberikan wewenang dengan tanggung jawab untuk berusaha agar kredit itu lancar dan menguntungkan.

\section{Organisasi dan Manajemen Kredit}

Manajemen kredit yaitu pengumpulan data dan penyajian informasi perkreditan dan pengelolaan kredit yang baik. Dalam organisasi dan Manajemen kredit memiliki petinggi-petinggi mulai dari dewan komisaris, direksi, permohonan kredit, pembukaan, account officer dan bagian angsuran dimana tanggung jawab dan bertugas menganalisis calon debitur dan melakukan pengawasan kredit.

\section{Proses Persetujuan Kredit}

Proses persetujuan kredit akan dimulai dari permohonan secara tertulis dan lengkap kemudian dalam menganalisis calon debitur harus menggunakan prinsip 5C yaitu Character, Capacity, Capital, Collateral dan Condition of Economy. Setelah perjanjian kredit telah disetujui oleh PT. Bank Perkreditan Rakyat Ganto Nagari 1954 Lubuk Alung Kabupaten Padang Pariaman maka persetujuan pencairan kredit untuk sebaiknya lebih mengoptimalkan prinsip 5C agar tercapai tujuan kredit yang diinginkan.

\section{Dokumen dan Administrasi Kredit}

Administrasi kredit adalah pengelolaan atas arsip yang ada sewaktu kredit tertera berlangsung. Pada PT. Bank Perkreditan Rakyat Ganto Nagari 1954 Lubuk 
Alung Kabupaten Padang Pariaman dokumen dan administrasi kredit sudah sesuai dengan prosedur kredit yang di jalankan dan telah dilakukan pengecekan keabsahan dokumen dengan benar lengkap dan juga akurat.

\section{Pembinaan dan Pengawasan Kredit}

Pengawasan kredit yaitu untuk pengendalian perwujudan kredit oleh bank dan nasabah supaya ketentuan dan incaran yang disimulasikan bisa dipenuhi sebagaimana persetujuan kredit. Dalam melakukan pembinaan dan pengawasan PT. Bank Perkreditan Rakyat Ganto Nagari 1954 Lubuk Alung Kabupaten Padang Pariaman dalam memberikan kredit pada nasabah telah dilaksanakan sesuai dengan ketentuan yang berlaku.

\section{Proses Penyelesaian Kredit Bermasalah}

Dalam pemberian kredit banyak menghadapi berbagai hambatan yang dapat mengakibatkan terjadinya kredit bermasalah. Kredit macet atau kredit bermasalah haruslah diselesaikan secepat mungkin agar kerugian yang besar dapat dihindari.

PT. Bank Perkreditan Rakyat Ganto Nagari 1954 Lubuk Alung Kabupaten Padang Pariaman pertama melakukan peringatan secara lisan, memberitahu mengenai jatuh tempo, batas waktu kepada debitur untuk melaksanakan pembayaran.

Proses penyelesaian kredit bermasalah jika terjadi kesalahan pada pengelolaan kredit yaitu langkah-langkah untuk megantisipasinya:

a. Penurunan suku bungan kredit, bertujuaan untuk melakukan kemudahan untuk debitur melalui pengurangan bunga kredit, sehingga angsuran yang dibayar oleh debitur lebih kecil.

b. Pengurangan tunggakan bunga kredit, bisa dilakukan melalui cara mengurangi tunggakan bungan kredit atau menghapus sebagian tunggakan bunga kredit.

c. Perpanjang jangka waktu kredit, yang bertujuan untuk mengembalikan hutang, melalui perpanjangan jangka waktu kredit memberikan kesempatan pada debitur untuk melanjutkan usahanya.

Tingkat Perkembangan Jumlah Kredit Yang diberikan dan Kredit Bermasalah

Tabel 2

Tingkat Perkembangan Jumlah Kredit Yang Diberikan dan Kredit

Bermasalah pada PT. Bank Perkreditan Rakyat Ganto Nagari 1954

Lubuk Alung Kabupaten Padang Pariaman

Periode 2017-2019

(Dalam Rp.000)

\begin{tabular}{ccccc}
\hline Tahun & $\begin{array}{c}\text { Total Kredit } \\
\text { yang Diberikan }\end{array}$ & $\begin{array}{c}\text { Kenaikan/ } \\
\text { pengurangan (\%) }\end{array}$ & $\begin{array}{c}\text { Total Kredit } \\
\text { Bermasalah }\end{array}$ & $\begin{array}{c}\text { Kenaikan/ } \\
\text { pengurangan (\%) }\end{array}$ \\
\hline 2017 & $21.895,300$ & 0 & $1.263,359$ & 0 \\
2018 & $23.476,193$ & 7,22 & 896,791 & -30 \\
2019 & $23.683,474$ & 0,8 & 890,499 & $-0,70$ \\
\hline
\end{tabular}

Sumber : www.Ojk.com, data olahan 
Berdasarkan tabel 2 dimana terlihat jumlah kredit yang diberikan pada periode 2017-2018 adalah sebesar 7,22\% dan pada periode 2018-2019 meningkat menjadi sebesar $0.8 \%$ Sedangkan jumlah kredit bermasalah pada periode 2017-2018 mengalami penurunan sebesar $-30 \%$ dan pada periode 2018-2019 mengalami penurunan sebesar $-0.70 \%$

\section{SIMPULAN}

Berdasarkan analisis pengelolaan kredit dengan menggunakan analisis laporan keuangan dan analisis tingkat perkembangan jumlah kredit yang diberikan dan kredit bermasalah pada PT. Bank Perkreditan Rakyat Ganto Nagari 1954 Lubuk Alung Padang Pariaman dari tahun 2017 sampai dengan tahun 2019 dapat diperoleh kesimpulan yaitu : pada periode 2017-2018 jumlah kredit bermasalah mengalami penurunan sebesar -30\% dan pada periode 2018-2019 terjadi penurunan lagi sebesar $-0,70 \%$ dan ini membuktikan bahwa pengelolaan kredit yang dilaksanakan oleh PT. Bank Perkreditan Rakyat Ganto Nagari 1954 Lubuk Alung Kabupaten Padang Pariaman sudah berjalan dengan baik.

\section{UCAPAN TERIMA KASIH}

Penulis mengucapkan terima kasih kepada PT. Bank Perkreditan Rakyat Ganto Nagari 1954 Lubuk Alung Kabupaten Padang Pariaman yang telah mengizinkan dan membantu penulis dalam memperoleh informasi. Serta semua pihak yang telah membantu penulis dalam penyelesaian artikel ini.

\section{DAFTAR PUSTAKA}

Alanshari, F., \& Marlius, D. (2018). Prosedur Pemberian Kredit KPR Pada PT. Bank Tabungan Negara (Persero) TBK Cabang Pembantu Bukittinggi. https://doi.org/10.31227/osf.io/rsfhc

Amelia, L., \& Marlius, D. (2018). Pengendalian Kredit Dalam Upaya Menciptakan Bank Yang Sehat Pada PT. Bank Pembangunan Daerah Sumatera Barat Cabang Utama Padang. https://doi.org/10.31227/osf.io/kpc64

Asyari, A., \& Marlius, D. (2021). Proses Penyelesaian Kredit Bermasalah Pada PT. BPD Sumatera Barat Cabang Pasar Raya Padang. https://doi.org/10.31219/osf.io/3hfer

Guntara, I.Made Adi, and Ni Made Ari Yuliartini Griadhi. 2017. "PEnerapan Prinsip 5c Sebagai Upaya Perlindungan Terhadap Bank Didalam Menyalurkan Kredit." Kertha Semaya: Journal Ilmu Hukum 7(8):1-15.

Kasmir, D. 2014. "Bank Dan Lembaga Keuangan Lainnya.” Edisi Revisi.

Lubis, Irsyad. 2010. Bank Dan Lembaga Keuangan. USUpress. 
Al Qoroni, Uwes. 2015. “Analisis Pengelolaan Kredit Yang Efektif Guna Meningkatkan Profitabilitas (Studi Pada PT. Federal International Finance Rangkasbitung)." Jurnal Administrasi Bisnis 26(1).

Widayati, Ratna, and Misa Nora Andani. 2019. "Pelaksanaan Prinsip Kehati-Hatian Dalam Pemberian Kredit Konsumtif Pada Bank Nagari Cabang Siteba."

Widayati, Ratna, and Sepni Maiwati. 2019. "Aktivitas Pemberian Kredit Komersil Pada Bank Nagari Cabang Sijunjung."

Widayati, Ratna, and Winda Elo Mendari. 2019. "Upaya Penanganan Kredit Bermasalah Pada Bank Nagari Cabang Utama Padang."

Widyaningrum, Septian Fika. 2010. "Analisis Efektivitas Pengelolaan Kredit Dalam Upaya Peningkatan Tingkat Likuiditas Pada PT. BPR Grogol Joyo." 